\title{
QUANTIFICATION OF THE STRUCTURAL RESPONSE OF HISTORICAL CONSTRUCTIONS: INVESTIGATION OF THE STRAIN VARIATION AT THE ACROPOLIS CIRCUIT WALL
}

\section{ELENA KAPOGIANNI ${ }^{*}$, PRODROMOS PSARROPOULOS AND MICHAEL SAKELLARIOU}

\author{
National Technical University of Athens 9 Heroon Polytechniou str. \\ Zografou, 15780 Athens, Greece \\ email* : elkapogianni@mail.ntua.gr \\ email: mgsakel@mail.ntua.gr, email :prod@central.ntua.gr
}

Keywords: Historical Complex Sites, Acropolis, Strain Recordings, Masonry Wall, Structural Monitoring, Optical Fibre Sensors

\begin{abstract}
The current study aims to assist the preservation of the structural integrity of historical complex sites, utilizing smart instrumental monitoring / remote sensing. The main idea is that smart instrumental monitoring can provide important real-time information (records) of both the actual natural hazard(s) and the corresponding vulnerability, in terms of structural response and distress of structures and monuments of historically complex sites. The study focuses on the Acropolis Circuit Wall, where strain recordings via Smart Rod optical fibre sensors have been made possible. More specifically, wavelength recordings have been obtained and then converted into strain recordings, while the temperature influence has been taken into consideration. Furthermore, reference measurements have been defined during the initial system operation and then they are used for deduction of subsequent recordings. Strains recorded 2 and 1/2years after the initial system installation are shown, after the deduction of the reference measurements. Finally, strain variation between sensors located at the inner and outer side of the same optical fibre Smart Rod are shown.
\end{abstract}

\section{INTRODUCTION}

Constructions of high and of national importance are often threatened by a variety of natural hazards, which may lead to damages and / or extended failures, resulting in some cases to injuries, fatalities, or even natural disasters. These constructions can be referred also as critical structures and have high socio-economic interest. Given their significance, it is essential to identify, manage and mitigate their structural risk, which is directly related, not only to the natural hazards, but also to the structural vulnerability. Regarding the natural hazards, they can be classified into two board categories: geological and climatological / meteorological (Figure 1). Furthermore, certain geographical regions are characterized by moderate or high seismicity which leads to various earthquake-related geohazards, such as earthquake-triggered landslides, fault rapture and soil liquefaction phenomena. On the other hand, structural vulnerability depends on the design, construction and operational conditions, while the age of the 
construction plays also an important role. Structural risk assessment requires the quantification of the loading conditions (including the hazards), and the realistic assessment of structural vulnerability in terms of structural response. Furthermore, climate change phenomena are related to the increase of the structural risk [1].

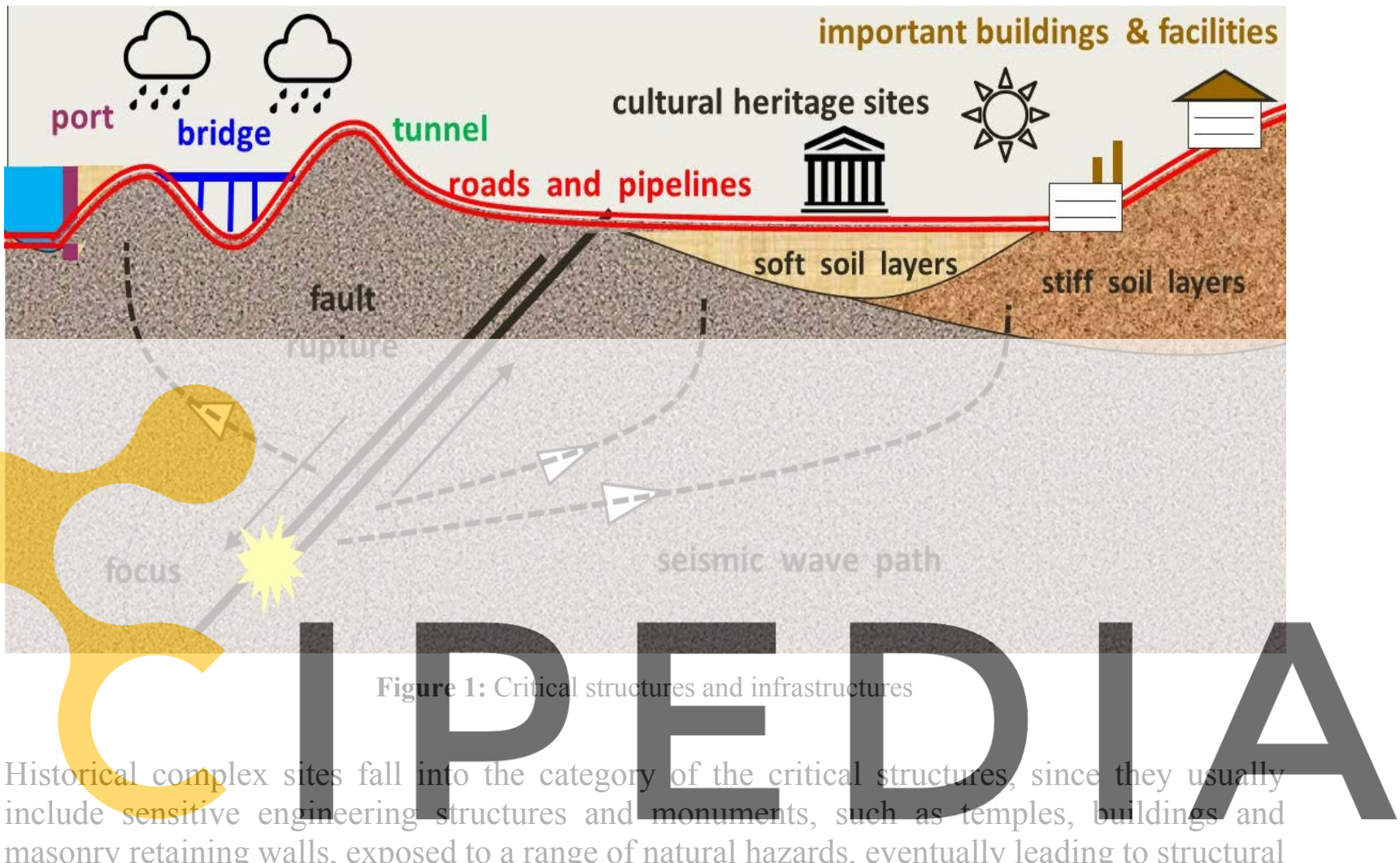

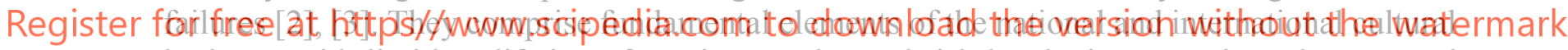
heritage, with limitless lifetime, featuring an elevated risk level, since a serious damage and especially a total failure of a structure and/or monument is practically irreversible. In addition, historical complex sites attract high numbers of visitors / tourists, and a potential structural failure due to insufficient risk management could have a direct impact on their safety, while potential intervention options are rather limited. Due to these reasons, the cost-efficient assessment and management of their structural risk forms a demanding task in comparison to a similar analysis applied to modern structures.

For the evaluation of the structural risk, quantitative hazard assessment and realistic evaluation of the structural vulnerability are indispensable. The risk assessment can be performed utilizing advanced computational simulations, smart instrumental monitoring. The advanced computational simulations (such as numerical modelling utilizing finite element software) can predict the expected response and distress of the structure(s) under examination when subjected to the anticipated natural hazard(s), being thus essential for the vulnerability assessment. On the other hand, smart instrumental monitoring can provide real-time information (i.e., records) of both the actual natural hazard(s) and in parallel the corresponding vulnerability, in terms of 
structural response and distress, leading to a dynamic (i.e., time-dependent) structural risk assessment.

In the current study the historical complex site of the Athenian Acropolis is examined in the above framework. In Figure 2 the Acropolis Hill, the Parthenon, and the masonry Circuit Wall are shown.
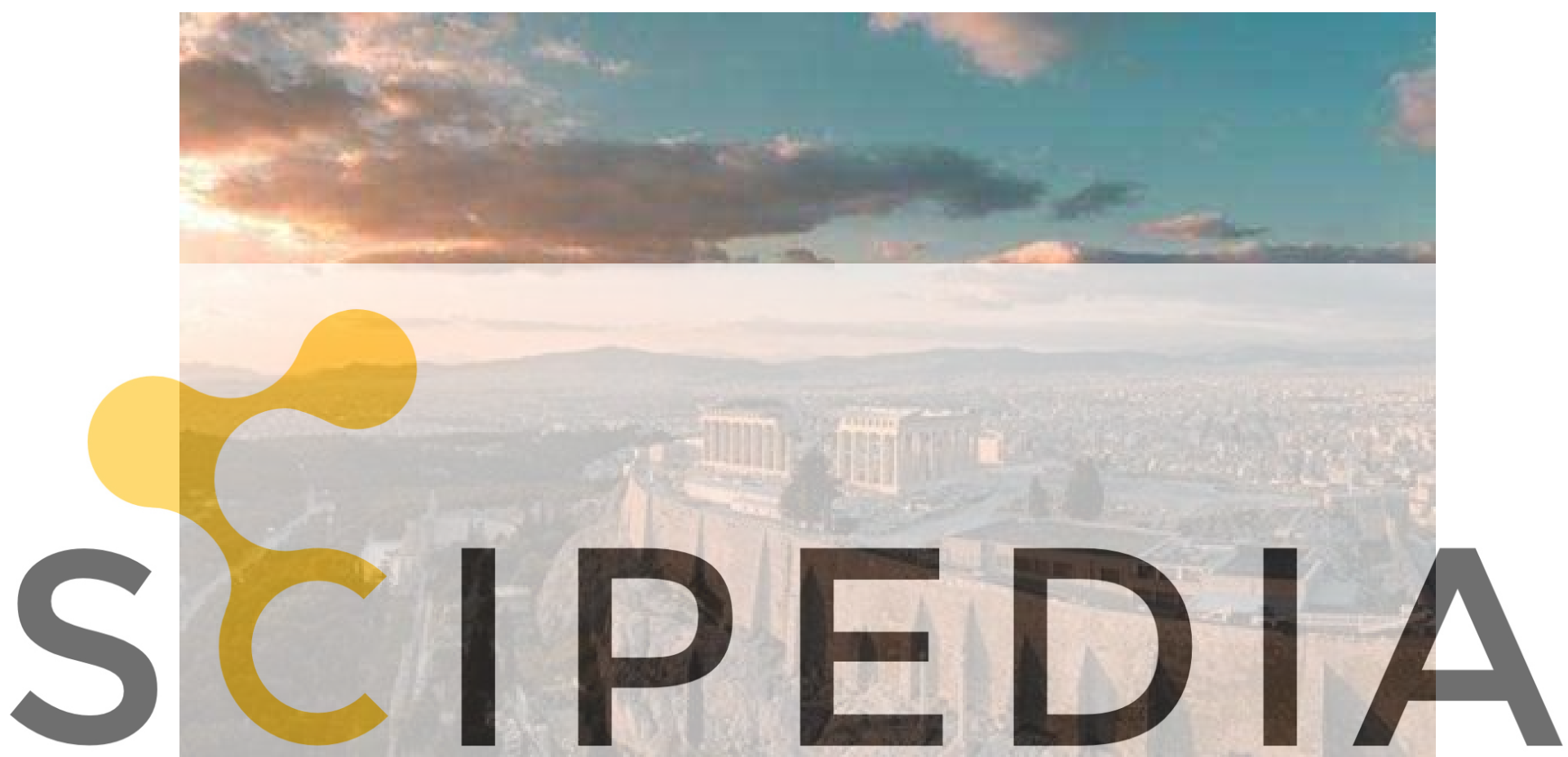

Register for free at https//www.scipedia.com to download the version without the watermark

Figure 2. The historical complex site of the Athenian Acropolis, including the Parthenon and the masonry Circuit Wall

\section{METHODS REVIEW AND APPLICATION AT THE ACROPOLIS OF ATHENS}

Smart structural monitoring/ remote sensing is a rapidly growing scientific area, traditionally applied to critical structures and infrastructures of national and economic importance comprising a high failure risk, aiming to their "smart" transformation [4], [5]. Apart from remote hazard assessment (i.e. assessment of the loading conditions), monitoring instruments can provide useful real-time information on specific location(s), necessary for the early detection of probable damage or failure during their lifetime, contributing thus to optimal risk management and overall safety. Furthermore, in an environment where various networks of sensors have been deployed, the need for intelligent management and processing of the recorded and transmitted data has emerged. Integral part of the data processing is the combination (i.e., 
data fusion between heterogeneous networks), [6] and the support of additional meta-data in order to efficiently handle the available measurements [7].

Regarding the computational modelling, numerical methods such as the finite-element method [8] can be applied to provide useful information regarding structural response and distress of any structure or monument. Usually, a computational simulation requires the geometrical and mechanical properties of the structure(s) and the anticipated static and dynamic loading, either external or internal. In order to achieve a more realistic simulation of the response / distress of a structure or a monument, the local site conditions (i.e., soil, geomorphology, and topography) and the corresponding potential soil-structure interaction should be taken into consideration.

Over the last twenty-five (25) centuries, numerous structural damages have been observed at the historical complex site of the Athenian Acropolis, which are attributed to various natural hazards (either geological or meteorological) and to the human interference (such as war invasions, air pollution, etc.), increasing in parallel the risk of local or extensive structural failures in the future. Given the potential natural hazards of Athens (mainly seismicity and meteorological conditions) and the great vulnerability of the structures / monuments on the site, the structural risk is considered to be very high [9], [10]. Furthermore, apart from the structural risk, the significance of the monuments and the safety of the visitors / tourists and employees make the assessment and management of the overall risk of the Acropolis of Athens issues of paramount importance.
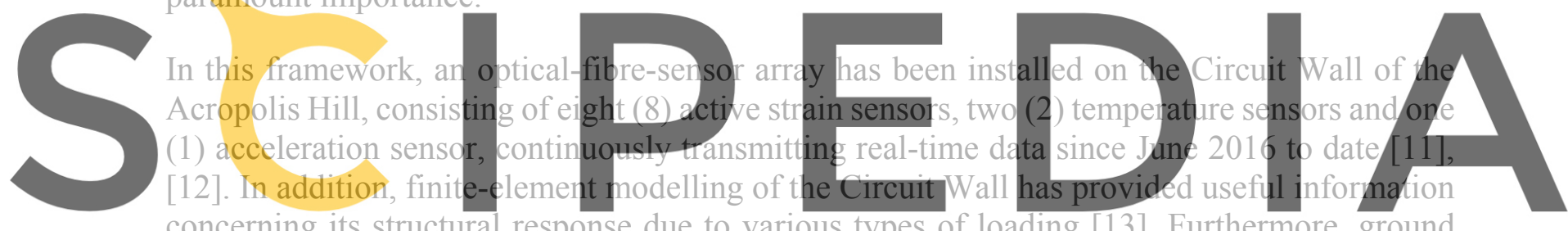
concerning its structural response due to various types of loading [13]. Furthermore, ground Register forponse analyes have been performed in order to investigate the impact of local site chnditions (1.e., topography) on the seismic motion at the ground surface of the Acropolis liti, as well as to verify the available records and comprehend the amplification. The seismic motions applied during the numerical analyses have been recorded by 10 high-quality broadband accelerographs installed at various locations at the Acropolis Hill, recording in continuous mode [14].

In Figure 3 part of the structural monitoring scheme of the Acropolis of Athens with optical fibre sensors $[15,16]$ can be seen and in Figure 4, part of the 2D numerical modelling of the Acropolis Circuit Wall and part of the 2D numerical modelling for the evaluation of the seismic response of Acropolis Hill. 


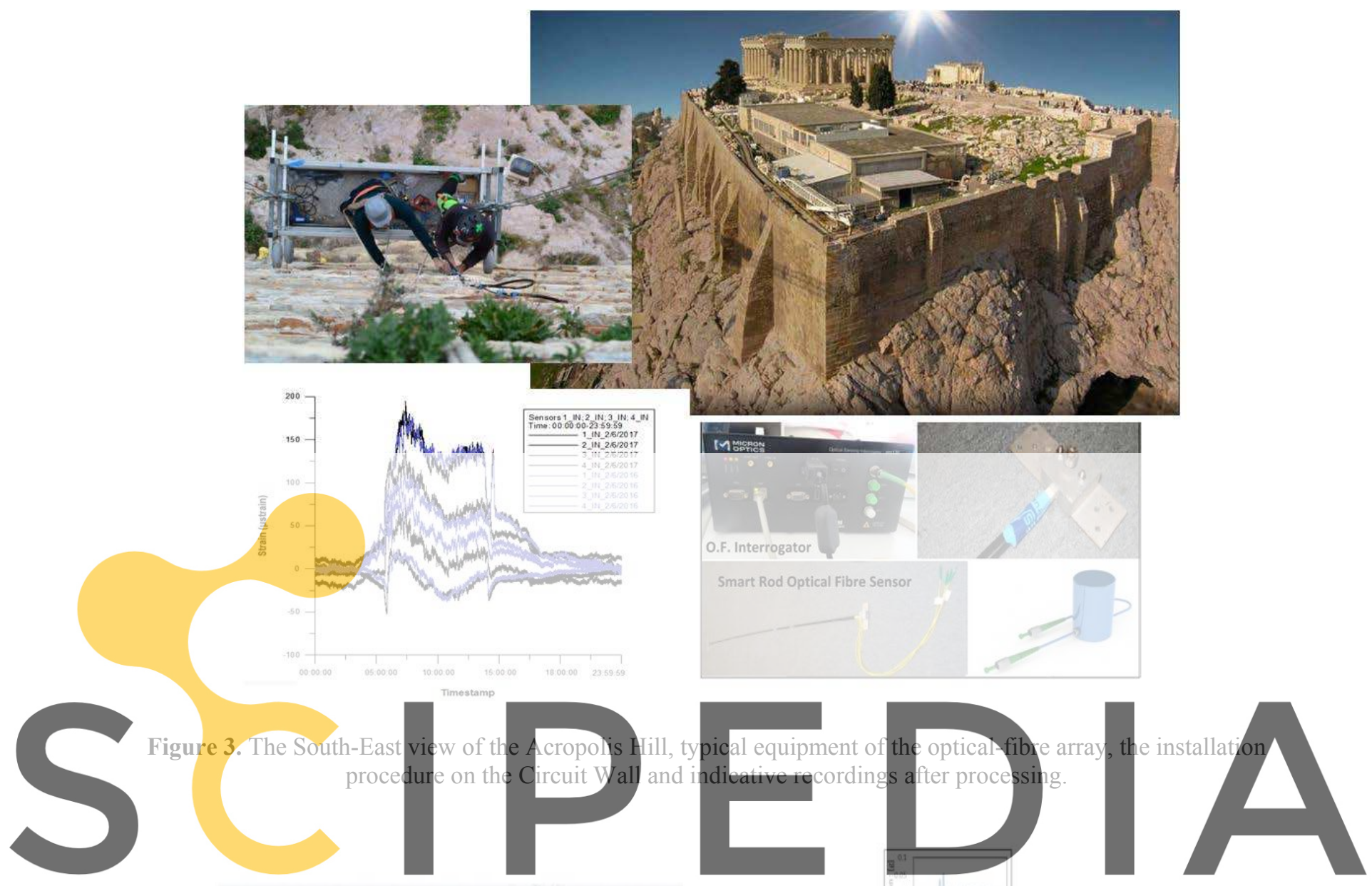

Register for free at https//www.scipedia.com to download the version without the watermark
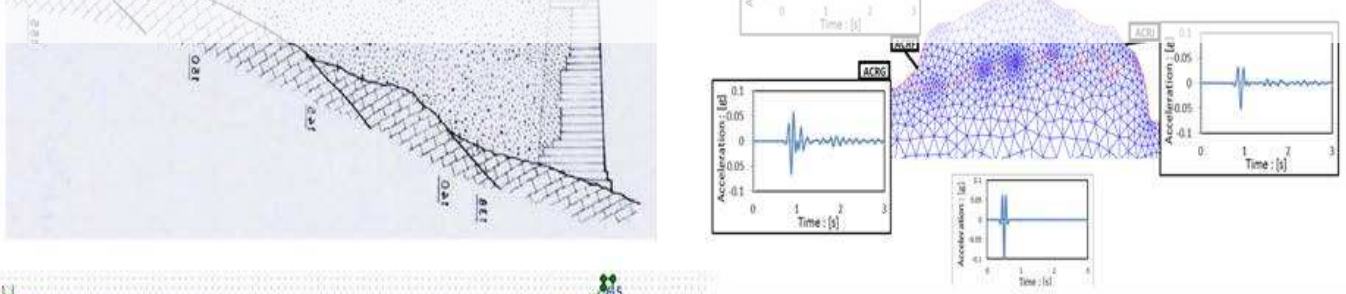

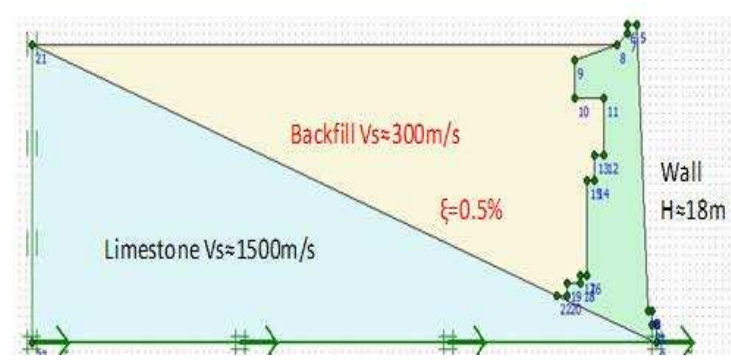

(a)

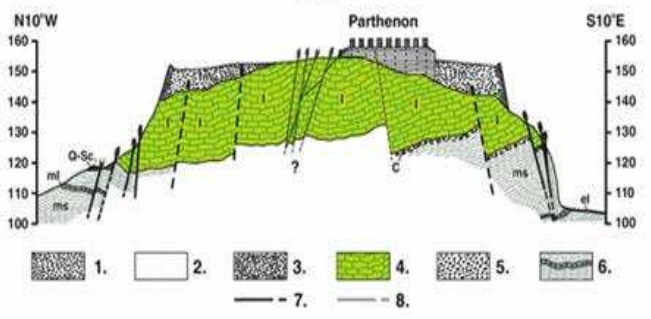

(b)

Figure 4. (a) Cross section sketch of the south Wall, and 2D numerical model, and (b) 2D numerical model for the evaluation of the seismic response of Acropolis Hill and geological cross section. 


\section{STRAIN VARIATION AT THE ACROPOLIS CIRCUIT WALL}

In this section recordings of the strain variation at the Acropolis Circuit Wall, with the use of optical fibre sensors are presented and discussed. As mentioned in the previous section, the optical fibre array consists of: (a) eight active strain sensors fixed every two, one on the inner side and one on the outer side of four Smart Rods, (noted as IN and OUT, respectively), and (b) two temperature sensors, fixed on one Smart Rod. The Smart Rods are attached on the Circuit Wall, transmitting time-stamped data since June 2016 to date. The influence of the temperature on the recordings is considered via thermal compensation. The wavelength changes were transformed into strains with the use of Equation 1.

$\Delta \varepsilon=\left(\Delta \lambda-K \tau^{*} \Delta \tau\right) / K \varepsilon$

where $\Delta \varepsilon$ is the strain change, $\Delta \lambda$ the wavelength change, $K \varepsilon$ is a ratio expressing the strainwavelength relation and is equal to 1.2 picometer $(\mathrm{pm}) / \mu$ strain for the type of sensors that was used in the current study, $\mathrm{K} \tau$. $\Delta \tau$ incorporates the wavelength changes due to the temperature variations. $\mathrm{K} \tau$ is equal to $11.2 \mathrm{pm} / \mathrm{C}^{0}$ for the sensors used in the current study, and $\Delta \tau$ is the temperature variation, measured during the tests (starting value and actual-final value).

In Figure 5a, the 9-day period of initial strain recordings on the Circuit Wall, via sensor 1 IN, are shown, and in Figure 5b, the average of these recordi initial strain recording average of these recordi the monitoring systenn and is deducted from subsequent recordings.
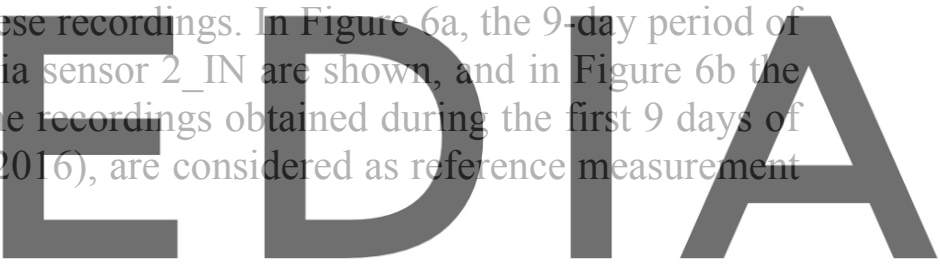

Register for free at https//wwww.scipedia.com to download the version without the watermark

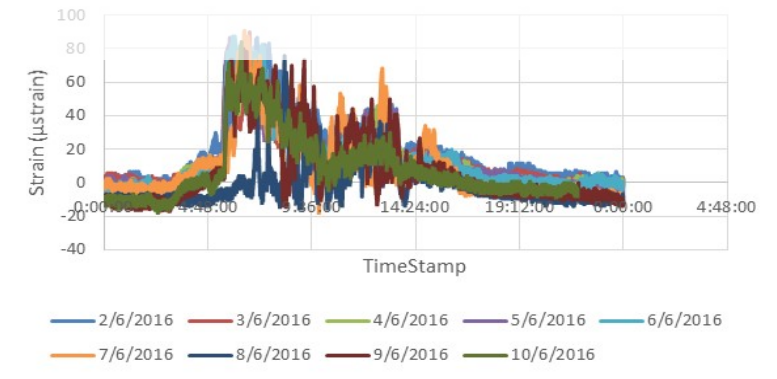

(a)

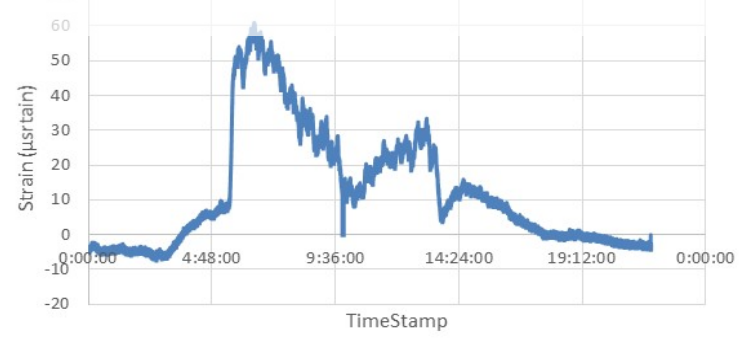

(b)

Figure 5. (a) Strain recordings via sensor 1_IN during a 9-day period, (b) average (reference) strain recordings via sensor 1_IN. 


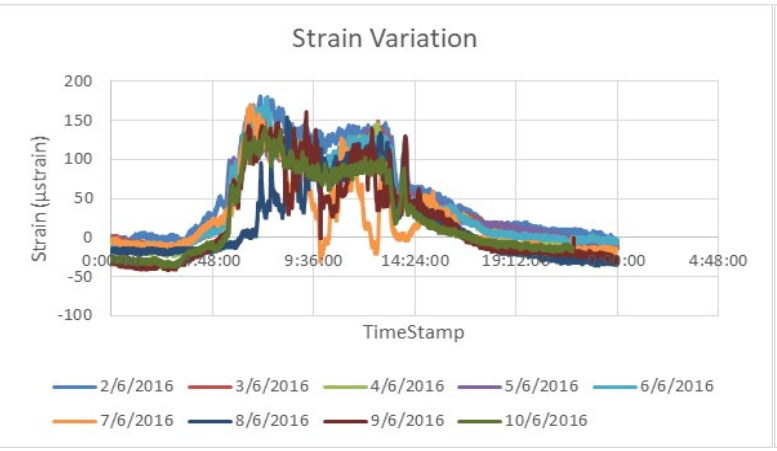

(a)

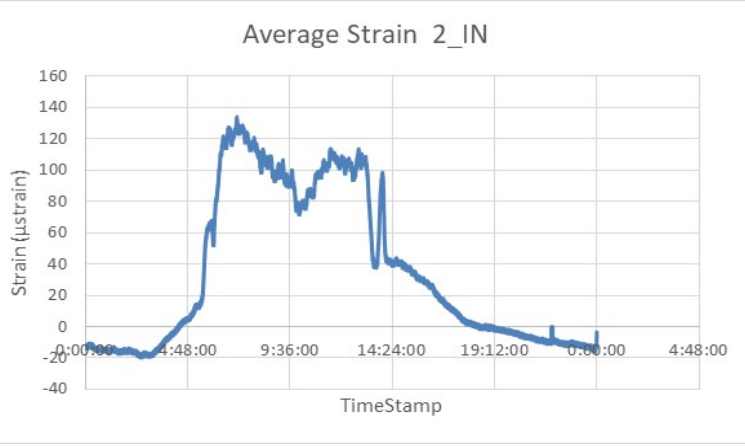

(b)

Figure 6. (a) Strain recordings via sensor 2 IN during a 9-day period, (b) average (reference) strain recordings via sensor 2 IN.

In Figures 7a and 7b, recordings during January 2018 for sensors 1_IN and 2_IN respectively, in comparison to the reference measurements of 2016 are shown. Furthermore, in Figures 8a and $8 \mathrm{~b}$, recordings before and after the deduction of the reference measurements are noted, for sensors 1 IN and 2_IN respectively.

Strain Variation

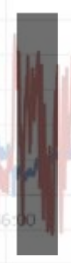

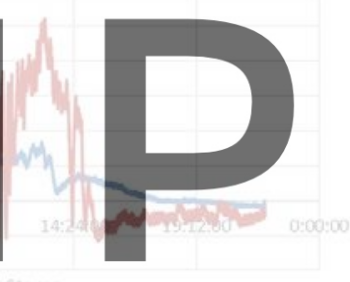

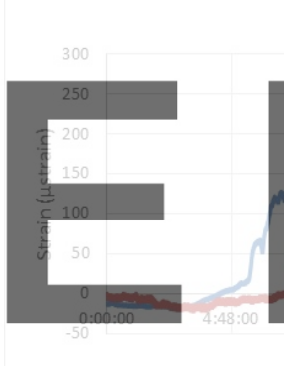
Strain Variation
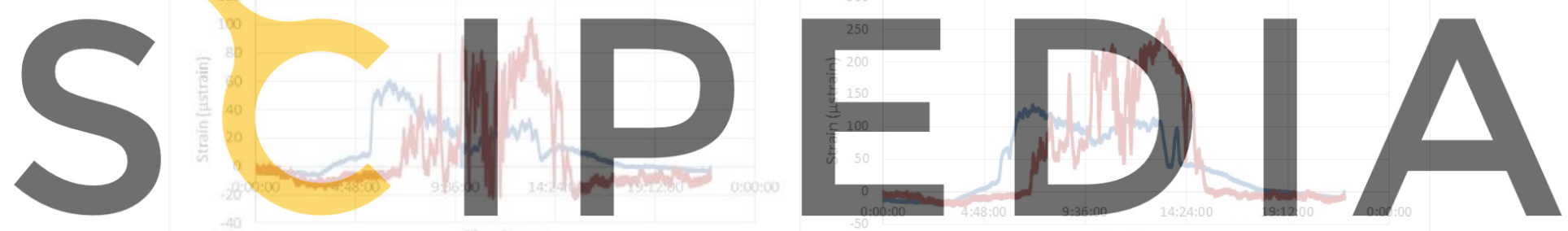

Register for free at https//www.scipedia.com to download the version without the watermark (a)

Figure 7. Recordings during January 2018 via sensors 1 IN (a) and 2 IN (b), in comparison to the reference measurements of 2016.

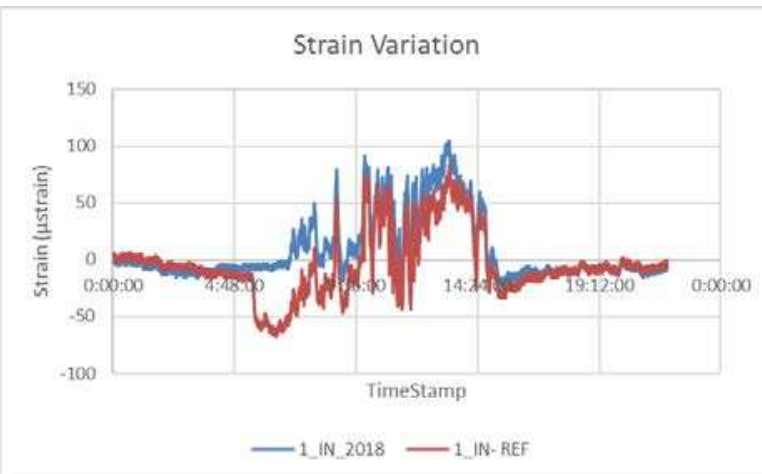

(a)

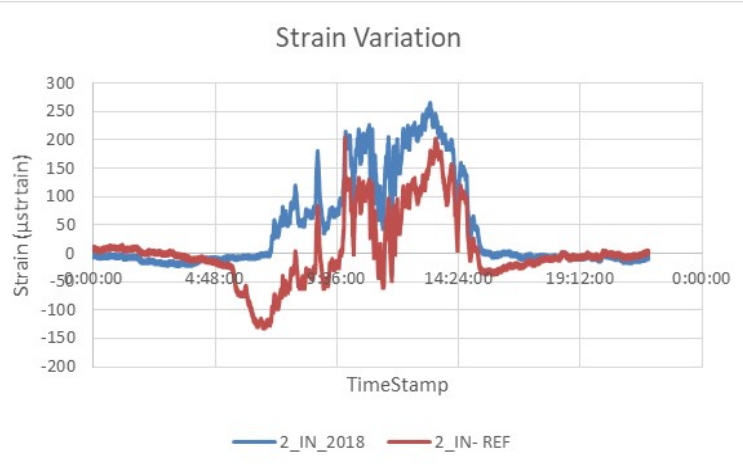

(b)

Figure 8. Recordings before and after the deduction of the reference measurements, via sensors 1_IN (a) and 2_IN (b). 
Finally, in Figures 9a, b, c and d, the strain variation between sensors located at the inner and outer side of the same Smart Rods, i.e. 1_IN and 1_OUT, 2_IN and 2_OUT, 3_IN and 3_OUT, 4_IN and 4_OUT, respectively are shown.

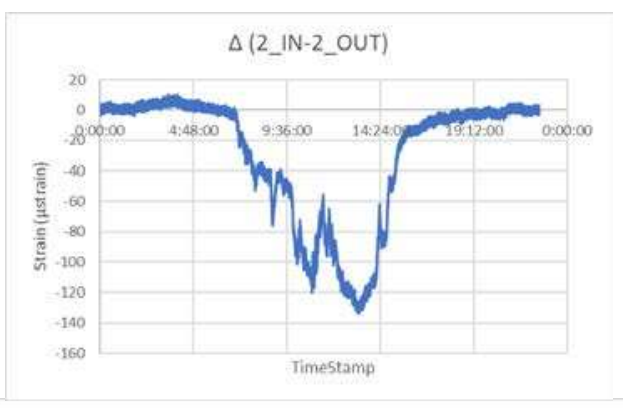

$\Delta\left(1 \_\right.$IN-1_OUT $)$

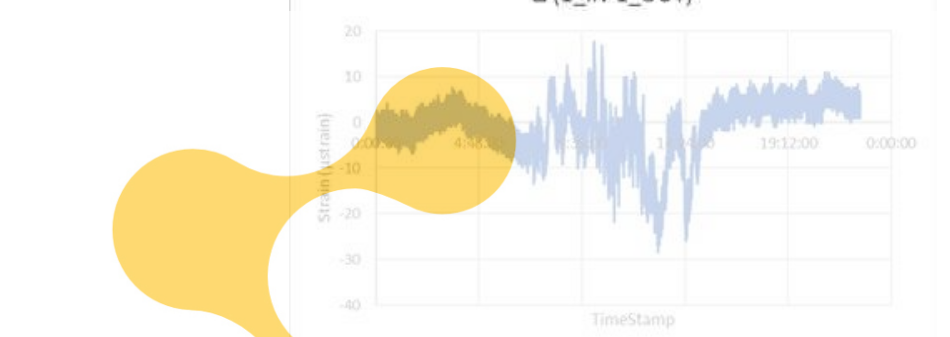

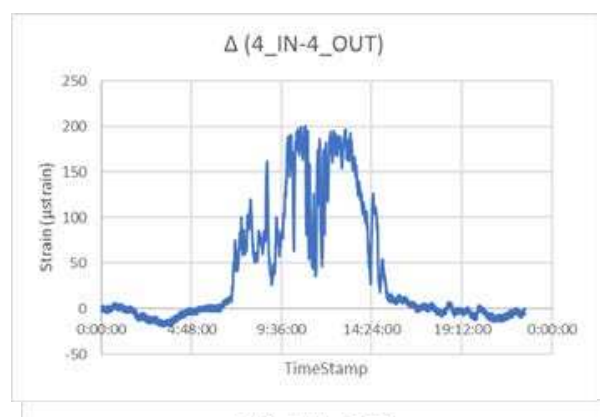

$\Delta\left(3 \_\right.$IN-3_OUT $)$

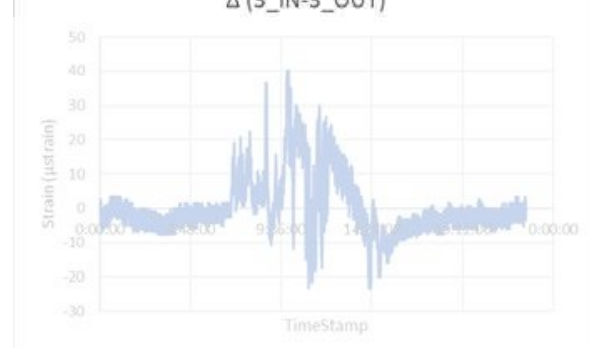

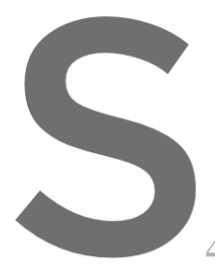
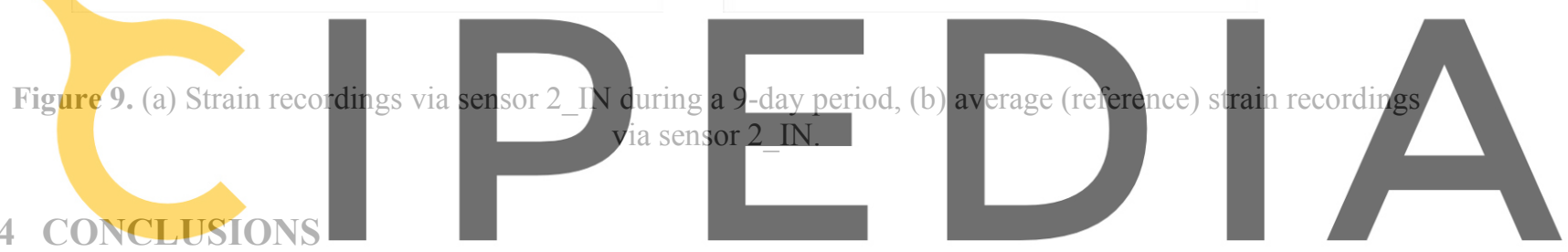

In the current study the strain.variation at the Acropolis Circuit Wall was investigated, with the

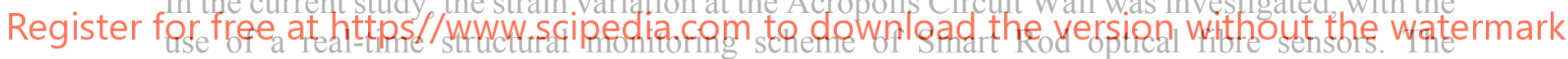

wavelength measurements obtained by the optical fibre sensors where converted into strain

measurements, while the temperature influence was taken into consideration via thermai compensation. At first, the period of strain recordings during the initial system operation in June 2016 was examined and the reference measurements were defined, as the average of the first days of the system operation recordings. Results of two of the eight sensors recording strain have been presented (i.e. sensors 1 IN and 2_IN). The reference measurements were used for the deduction of future strain recordings, always including thermal compensation.

In the above framework, recordings during January 2018 were compared to the reference measurements of June 2016, for sensors 1_IN and 2_IN, showing increased strains at the Circuit Wall, as expected. Furthermore, the initial strain recordings during January 2018 were compared to strains at the same locations on the Circuit Wall, after the deduction of the reference measurements, which were smaller as expected, and especially for sensor 2_IN. 
Finally, strain variation between sensors located at the inner and outer side of the same optical fibre Smart Rod was presented, showing that for Smart Rods 1, 3 and 4, higher strains were recorded by the sensors located at the inner side (i.e. closer to the Wall), and especially for Smart Rod 4, while for Smart Rod 2, higher strains were recorded by the sensor located at the outer side of the Smart Rod.

The current study and the conclusions can be used for future investigation and interpretation of the strain recordings at the Acropolis Circuit Wall. In addition, the method utilized, and the results can be potentially used for the structural monitoring of other critical structures of high importance, in order to define their structural response due to various types of loading. Finally, the current study aims to assist the transformation of historical complex sites / cultural heritage sites into "smart" which is expected to have a multiplier effect on the applied scientific knowledge enhancing the diffusion of new technologies and methods.

\section{ACKNOWLEDGMENTS}

The author is grateful for financial support provided by the State Scholarships Foundation of Greece (IKY). This research is co-financed by Greece and the European Union (European Social Fund- ESF) through the Operational Programme «Human Resources Development, Education and Lifelong Learning» in the context of the project "Reinforcement of Postdoctoral

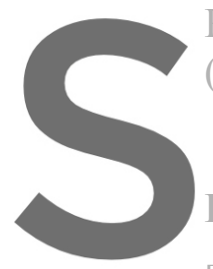
Researchers - 2nd Cy

(IKY).

REFERENCES
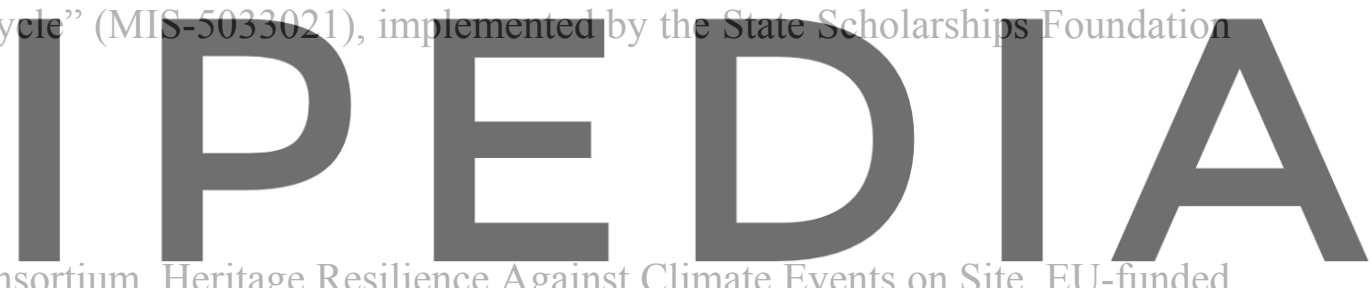

[1] HERACLES Consortium. Heritage Resilience Against Climate Events on Site. EU-funded

\section{Register for Research Programme (2019)}

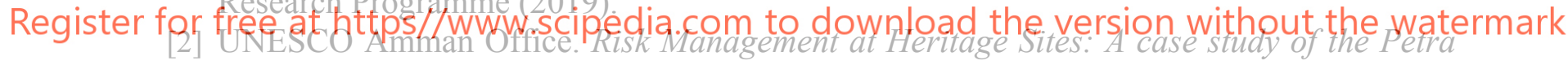
World Heritage Site. Project Report, Paris; Aman, (2012) p 128.

[3] ICOMOS, 1965. International Charter for the Conservation and Restoration of Monuments and Sites. $2^{\text {nd }}$ International Congress of Architects and Technicians of Historic Monuments, Venice, Italy.

[4] Kapogianni, E., Psarropoulos, P., Sakellariou, M. Securing the Future of Cultural Heritage Sites, Utilizing Smart Monitoring Technologies: From the Laboratory Applications to the Acropolis of Athens (2020) In: Correia A., Tinoco J., Cortez P., Lamas L. (eds) Information Technology in Geo-Engineering. ICITG 2019. Springer Series in Geomechanics and Geoengineering. Springer, pp 750-762.

[5] Chatzi, E. A Monitoring Approach to Smart Infrastructure Management. Journal: Proceedings (2017), 1(8), 755.

[6] Sun, D., Lee, V., Lu, Y. An intelligent data fusion framework for structural health monitoring. IEEE $11^{\text {th }}$ Conference on Industrial Electronics and Applications (2016).

[7] Vilbrandt, C., G. Pasko, A. Pasko, P-A. Fayolle, T. Vilbrandt, J. R. Goodwin, J. M. Goodwin, \& T. L. Kunii. Cultural Heritage preservation using constructive shape modeling, Computer Graphics Forum (2004) V23(1), pp. 25-41. 
[8] Kapogianni, E., Sakellariou, M.G., Laue, J., Springman, S.M., Investigation of the mechanical behavior of the interface between soil and reinforcement, via experimental and numerical modeling. Advances in Transportation Geotechnics 3. Procedia Engineering, Elsevier (2016) V143, 419-426.

[9] Ambraseys N. Material for the investigation of the seismicity of Central Greece, in Historical Investigation of the Seismicity of European Earthquakes. Albinii, P. and Moroni (eds.), (1994) V2: pp 1-10.

[10] Zambas C., Ambraseys N., Boletis C., Zampa I. The two Choragic Columns of the south slope of the Acropolis, as witnesses of the seismic history of the centre of Athens. Scientific Project Report, John Latsis Public Benefit Foundation (2011)

[11] Kapogianni, E., Kalogeras, I., Psarropoulos, P., Michalopoulou D., Eleftheriou, V., Sakellariou, M. Suitability of Optical Fibre Sensors and Accelerographs for the Multidisciplinary Monitoring of a Historically Complex Site: The Case of the Acropolis Circuit Wall and Hill. Journal: Geotechnical and Geological Engineering, Springer International Publishing (2019). Volume 37, Number 5, p 4405

[12] Kapogianni E., Kalogeras I., Psarropoulos P.N., Giokaris S., Sakellariou M.G., 2016. Structural health monitoring of the Athenian Acropolis' Walls via optical fibre sensors, accelerographs and numerical simulations. Structural Analysis of Historical Constructions: Anamnesis, diagnosis, therapy, controls. Van Balen, K.,Verstrynge, E. (eds), Taylor \& Francis Group, CRC Press (2016) 701-707.

[13] Psarropoulos P
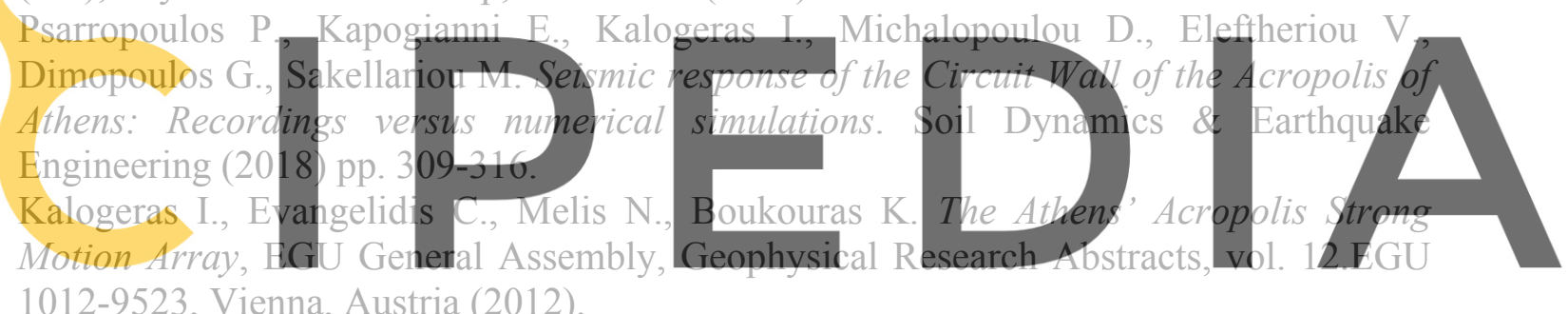

1012-9523, Vienna, Austria (2012).

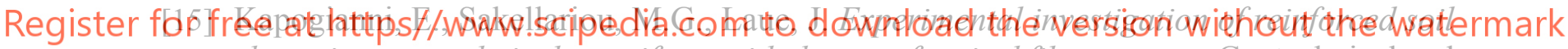
slopes in a geotechnical centrifuge, with the use of optical fibre sensors. Geotechnical and Geological Engineering, Springer International Publishing, (2017) V35(2), pp. 585-605.

[16] Kapogianni E., Psarropoulos P.N., Kokoris, D., Kalogeras I., Michalopoulou, D., Eleftheriou, V., Sakellariou M.G. 2020. Impact of Local Site Conditions on the Seismic Response of the Athenian Acropolis Hill. Geotechnical and Geological Engineering, Springer International Publishing. https://doi.org/10.1007/s10706-020-01589-8 